\title{
Treatment Strategies in Hepatocellular Carcinoma
}

\author{
Charles W. Kimbrough and Timothy M. Pawlik
}

Department of Surgery, The Ohio State University Wexner Medical Center, Columbus, $\mathrm{OH}$

\section{ABSTRACT}

Hepatocellular carcinoma (HCC) is the most common primary liver malignancy worldwide, and a leading cause of global cancer-related mortality. However, a multitude of risk factors results in heterogeneous tumor biology that can demonstrate widely different clinical behaviors. Chronic inflammation represents the predominant etiology of $\mathrm{HCC}$, and up to $80-90 \%$ of cases occur in the setting of cirrhosis. The underlying liver disease observed in most patients adds an additional level of clinical complexity not present in most other cancers. Careful consideration of the tumor biology, liver function, and the patient's performance status is necessary in order to select the best therapy. There exists a wide range of potential therapeutic options, and clinicians must know when to apply each. While early HCC can be managed with local control strategies such as surgical resection or ablation, more advanced tumors may be limited to loco-regional or systemic therapies. All tumors that meet criteria should be considered for liver transplantation. Often, the range of potential therapies will be limited by a patient's liver function and degree of cirrhosis. Additionally, in many cases there is insufficient evidence to clearly determine the best therapeutic option, and therefore these patients should be discussed within a multi-disciplinary tumor board. Future research is necessary to refine the optimal management strategy for HCC, including the role of novel treatments such as immunotherapy.

Key words: hepatocellular carcinoma, surgical resection, transplantation, liver-directed therapy, radiofrequency ablation

\section{INTRODUCTION}

Hepatocellular carcinoma (HCC) encompasses a broad spectrum of patients and possible treatment options. A diversity of risk factors and underlying etiologies gives rise to heterogeneous biology and tumors that can demonstrate widely different clinical behavior. In addition, HCC tends to emerge in the setting of advanced liver disease, adding a level of clinical complexity that is not present in most other cancers. The result is a difficult balancing act between treating patients' tumors and managing their underlying liver insufficiency. Successful treatment therefore requires a thorough understanding of the options available and when to apply each. In this review, we will provide a overview of HCC followed by an in-depth discussion of the appropriate treatment strategies.

\section{EPIDEMIOLOGY}

$\mathrm{HCC}$ is the most common primary liver malignancy and a leading cause of global cancer-related mortality. Although incidence varies greatly by region,
Corresponding author: Timothy M. Pawlik, MD, MPH, PhD, FACS FRACS (Hon.)

Professor and Chair, Department of Surgery

The Urban Meyer III

and Shelley Meyer Chair for Cancer Research Professor of Surgery, Oncology, Health Services Management and Policy The Ohio State University Wexner Medical Center 395 W. 12th Ave., Suite 670 Phone: 6142938701 Fax: 6142934063 E-mail: Tim.Pawlik@osumc.edu

Received: 30.03.2018

Accepted: 15.04.2018

Copyright (ㅇ Celsius Publishing House www.sgo-iasgo.com 
worldwide $\mathrm{HCC}$ is the $5^{\text {th }}$ most common cancer in men and the $7^{\text {th }}$ most common in women (1). The highest incidence is observed in areas with endemic hepatitis $B$, such as Sub-Saharan Africa or Eastern Asia. In these regions, the incidence often exceeds 20 per 100,000 persons. Much of Southern Europe and the Mediterranean has an intermediate incidence of 5-10 per 100,000. The overall incidence is low $(<5$ per 100,000$)$ in Northern Europe and the Americas $(1,2)$. Nevertheless, in the United States HCC represents one of the fastest rising causes of cancer mortality. Over the last several decades, there has been a three-fold increase in the incidence of HCC from 1.4 per 100,000 in $1975-77$ to 4.8 per 100,000 in 2005-07 (3,4).

Chronic inflammation from a number of different risk factors represents the predominant etiology of HCC, and up to $80-90 \%$ of cases occur in the setting of cirrhosis (5). The hepatitis B virus (HBV) is the leading cause worldwide, particularly in developing countries where it is mostly acquired through vertical or perinatal transmission. In developed countries, acquired hepatitis $\mathrm{C}$ virus (HCV) or alcohol abuse are the most common causes of HCC. Given the emerging obesity epidemic, non-alcoholic fatty liver disease (NAFLD) or nonalcoholic steatohepatitis (NASH) are increasingly associated with cirrhosis and an elevated risk for HCC. Additional cofactors that contribute to the development of HCC include tobacco inhalation and aflatoxin B1, a fungal carcinogen that contaminates food products in moist environments $(1,6)$.

\section{HISTOLOGY}

Although chronic inflammation is a common underlying mechanism in the development of HCC, HCC pathogenesis encompasses a wide variety of different molecular pathways and alterations to the tumor microenvironment (7). In fact, HCC tumors from disparate geographic regions may demonstrate different histologic growth patterns or subtypes according to the predominant etiology and underlying population risk factors (8-10). HCC is remarkable for its heterogeneous biology, but these tumors all likely progress along a spectrum from regenerative or dysplastic nodules to HCC $(8,11)$. Early HCC classically present as small lesions $(<2 \mathrm{~cm})$ with well-differentiated histology and poorly defined margins. Progressed HCC are generally larger $(>2 \mathrm{~cm})$, and are moderate to poorly-differentiated with nodular, massive, or diffuse patterns of growth $(8,12)$. In addition, HCC may appear as a solitary nodule or as multiple tumors. Multi-focal HCCs represent either independent synchronous lesions or satellite metastases from a solitary progenitor tumor, and often reflect a more aggressive biology with an increased likelihood of recurrence following therapy.

Various histologic subtypes of hepatocellular carcinoma have also been described, although the clinical significance of each is not always clear $(9,10)$. One histologic variant with clear clinical implications is fibrolamellar HCC. This rare subtype is generally seen in young female patients without cirrhosis or other known risk factors for HCC. Although these patients can have relatively large tumors at presentation, if amenable to surgical resection or transplant the prognosis is favorable compared to classic HCC. On the other hand, fibrolamellar HCC are considered less responsive to systemic therapy than other forms of HCC, although multimodality and locoregional therapies remain an option (13).

\section{DIAGNOSIS}

Historically, patients with HCC present with vague abdominal complaints such as pain or symptoms related to their underlying liver disease. As a result, many patients are initially diagnosed late in the disease course with intermediate or advanced tumors, with an estimated 5-year survival of only $12 \%(14,15)$. Even for early stage disease, survival can be measured in months (median overall survival 13.4 months) if left untreated (15). With treatment, the overall 5-year survival approaches $75 \%$ for early stage disease, whereas 3-year survival for intermediate stages may be as high as $60 \%$ (6). The impact of early treatment for HCC has led to the development of screening protocols for high-risk populations. Evidence suggests that tumors are not only identified before they are clinically apparent, but also that surveillance leads to improved overall survival $(16,17)$. Current recommendations suggest screening high-risk patients every 6 months with abdominal ultrasound (18). While the tumor marker alpha fetoprotein (AFP) may aid with diagnosis in the setting of a known mass, it has not proven useful for surveillance (18).

Lesions identified on ultrasound that are larger than $1 \mathrm{~cm}$ or incidental findings from other studies should be evaluated with contrast-enhanced imaging. Nodules less than $1 \mathrm{~cm}$ can be followed with close ultrasound surveillance, as the majority of these lesions will not be HCC. Specific pathognomonic features of HCC can be distinguished on contrast enhanced CT or MRI, such that diagnosis can often be made based on imaging characteristics alone. In particular, HCC lesions will appear hyper-enhancing during early phases following 
contrast administration, with increased intensity compared to the background liver. On delayed phases, HCC tumors will "washout," and appear hypo-intense compared to normal liver parenchyma. In order to better classify liver lesions, radiologists have incorporated arterial enhancement, delayed washout, tumor diameter, capsule appearance, and the growth rate into a diagnostic algorithm for HCC - the Liver ImagingReporting and Data System (LI-RADS) $(19,20)$. Similar to the BI-RADS system used in breast cancer, tumors are classified along a spectrum from benign to definitely HCC (see table 1). Biopsy can be considered for equivocal cases without classic imaging findings.

\section{STAGING}

Cancer staging systems perform two principal functions - stratification of patients into categories for accurate prognostic assessment and guidance of treatment decisions. For most cancers, both prognosis and treatment decisions can largely be determined from the clinical or pathologic stage. However, such staging systems have proven inadequate for HCC. For instance, although recently updated in 2017, the American Joint Committee on Cancer (AJCC) staging for HCC largely remains a pathologic staging system based on the tumor-node-metastasis (TMN) model. While AJCC TMN staging adequately discriminates survival among patients that have undergone surgical resection, as few as $5-10 \%$ of HCC patients may ultimately be surgical candidates $(21,22)$. Most of these patients are not surgical candidates due to other factors that affect prognosis in HCC.

In addition to tumor stage, prognosis in HCC depends upon functional status, the degree of any underlying liver disease, and the type of treatment delivered. Over the years, multiple staging systems have been developed that incorporate any number of these factors in order to better guide prognosis and treatment decisions for HCC (23-28). Nonetheless, many of these systems have not proven reproducible, and most have not been universally accepted. Of the alternate staging systems, the most widely adopted has been the Barcelona Chronic Liver Clinic (BCLC) staging system. The BCLC classification divides patients into 5 categories based upon tumor characteristics, liver function, and health status. A therapy algorithm allocates patients into the appropriate treatment category, with an associated prognosis (see fig. 1). Although useful as a starting framework, patients may not always fit neatly into one of the defined categories and are subject to 'treatment stage migration' (18). It is imperative that physicians still evaluate and individualize therapy for each patient. Regardless, the BCLC classification has been endorsed by the European Association for the study of the Liver (EASL) and the American Association for the Study of Liver Diseases (AASLD) (18).

\section{TREATMENT STRATEGIES}

The overall goal of care for HCC is to extend survival while maintaining good quality of life, but in reality successful treatment can range from cure of early stage HCC to palliation in advanced disease. Therapeutic options include local therapies such as surgery or ablation, arterially-directed regional therapies, systemic therapy, and liver transplant. Selection of the appropriate treatment requires careful consideration of the tumor biology, the extent of any underlying liver disease, and patient level factors such as performance status. In many

Table 1 - Liver Imaging-Reporting and Data System (LI-RADS) Classification for hepatocellular carcinoma (HCC)

\begin{tabular}{lll}
\hline LI-RADS Score & Classification & Management \\
\hline LR-1 & Benign & Continue routine surveillance \\
\hdashline LR-2 & Probably benign & Continue routine surveillance \\
\hdashline LR-3 & Intermediate probability of HCC & $\begin{array}{l}\text { Variable follow-up depending on size, stability, and } \\
\text { clinical presentation }\end{array}$ \\
& Probably HCC & $\begin{array}{l}\text { Close follow-up, biopsy, additional imaging, or } \\
\text { definitive treatment }\end{array}$ \\
\hline LR-4 & Definite HCC & Treatment without biopsy \\
\hline LR-5 & Cannot be classified due to image degradation or omission \\
\hline Additional LI-RADS Classifications & \\
\hline LR-NC & Definite tumor in vein \\
\hline LR-TIV & Probably or definitely malignant but not HCC \\
\hline
\end{tabular}




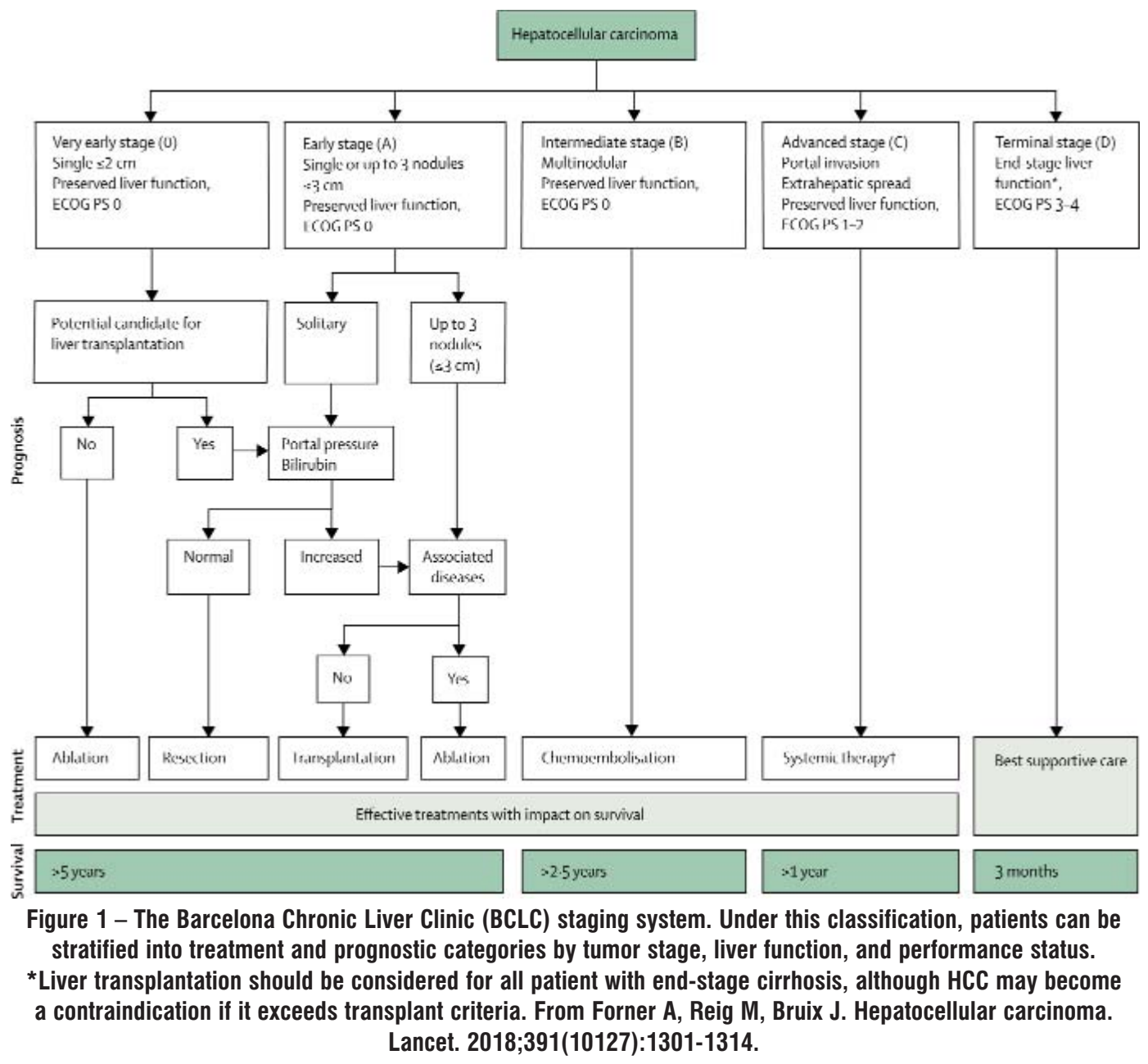

instances, evidence to guide therapy is lacking or of low quality, as much of the literature consists of small retrospective cohort studies or underpowered clinical trials $(21,29,30)$. Given the complexity of this disease, the relative lack of high-quality evidence, and the multitude of treatment options, HCC patients should be discussed in the setting of a multi-disciplinary tumor board.

\section{LOCAL THERAPY}

\section{Assessment of liver function and resectability}

Surgical resection is reserved for patients without cirrhosis or with those well-compensated liver disease in the absence of portal hypertension (BCLC stage $0 / A$ ). In addition to removing the tumor, resection should leave sufficient functional liver volume to prevent postoperative hepatic failure. While in general this limits surgery to Child-Pugh class A patients, careful evaluation of synthetic liver function extends beyond the Child-Pugh classification. Laboratory evaluation should reveal a normal serum bilirubin, normal coagulation

studies, and a platelet count greater than $100,000 / \mu \mathrm{L}$. Guidelines vary as to exact laboratory cut-offs for resection; for instance both AASLD and EASL recommend a bilirubin less than $1 \mathrm{mg} / \mathrm{dL}$, while Asian centers often use a value of $<2 \mathrm{mg} / \mathrm{dL}$ (29). A reasonable approach is to consider resection in patients with a total bilirubin and INR both less than 1.5. Assessment of liver function with the model for end-stage liver disease (MELD) may also be predictive of post-operative morbidity and mortality. In one series of 82 patients that underwent resection for HCC, patients with a MELD score $\leq 8$ had no associated perioperative mortality, versus a perioperative mortality of $29 \%$ in patients with a MELD $>8$ (31).

In addition to adequate biochemical function, careful review of imaging should rule out signs of portal hypertension such as ascites, varices, or splenomegaly. Thrombocytopenia with platelets less than $100,000 / \mu \mathrm{L}$ is also suggestive of portal hypertension and splenic sequestration. Direct quantification of portal hypertension through measurement of the hepatic venous 
pressure gradient (HVPG) is rarely performed, although a HVPG cutoff of $\geq 10 \mathrm{mmHg}$ has been associated with an increased risk of post-operative hepatic decompensation (32). Liver stiffness as measured by non-invasive transient elastography (FibroScan) is an additional modality that can identify portal hypertension and predict outcome following resection (33).

If a patient's baseline liver function meets criteria for resection, the tumor must be carefully assessed for resectability. There are several considerations, including size, vascular invasion, the number of tumors, and the location within the liver. Invasion of the main portal vein and extrahepatic disease are contraindications to resection. Multifocal tumors and microvascular invasion are not strict contraindications, although they are both markers for increased risk of recurrence and resection must be weighed against other therapies (18). Anatomic resections may be preferred, as wider margins have been shown to impact survival (34). Nonetheless, the functional liver remnant (FLR) must also be taken into consideration, with an FLR of $40-50 \%$ required in the setting of cirrhosis. In a healthy liver, a FLR of $20 \%$ may be acceptable, although at least $30 \%$ is preferred following chemotherapy. Portal vein embolization has proven safe and effective to increase the FLR, even in the setting of cirrhosis and HCC (35).

\section{Non-cirrhotic HCC}

In non-cirrhotic patients, surgical resection is the treatment of choice. Although patients without cirrhosis tend to present with more advanced tumors, neither size nor multifocality are considered a strict contraindication, and major hepatic resections can be performed safely $(36,37)$. Surgery can be performed even for large tumors $>10 \mathrm{~cm}$, with results comparable to the resection of smaller tumors $(38,39)$. In noncirrhotic patients, the 5-year overall survival exceeds $50 \%$ following successful resection (40). Nonetheless, recurrence rates approach $70 \%$ at 5 years, with multifocality, tumor size, vascular invasion, and poor differentiation predictive of increased recurrence or decreased survival $(40,41)$.

\section{Very Early HCC}

For patients with well-compensated cirrhosis without portal hypertension, surgical resection must be balanced against the role of transplantation and other therapies. Key factors to consider include the size and number of tumors. Patients with very early HCC (solitary lesions $<2 \mathrm{~cm}$ ) should be evaluated for either resection or ablation. Several randomized controlled trials have compared resection to ablation in early HCC, although results were mixed and no trial looked specifically at lesions $<2 \mathrm{~cm}(42-44)$. A propensity score model comparing resection and ablation in tumors $<2$ $\mathrm{cm}$ demonstrated improved overall and disease-free survival following surgical resection (45). In patients with more advanced liver disease or with portal hypertension, ablation is generally the preferred therapy for tumors $<2 \mathrm{~cm}$. However, some authors advocate close observation, thereby allowing the patient to become eligible for liver transplant once the lesion exceeds $2 \mathrm{~cm}$ (46). Patients must be closely followed; under a protocol of serial imaging every 3 months, Mehta et al. demonstrated a $9 \%$ chance of progression beyond Milan criteria at one year (46).

\section{Early HCC}

Once patients with cirrhosis develop solitary tumors $\geq 2 \mathrm{~cm}$ or multifocal disease, they should be evaluated for liver transplant. For eligible patients, liver transplant is considered the best treatment option and theoretically treats not only the HCC, but also the patient's underlying cirrhosis. The Milan criteria, defined as a single nodule $\leq 5 \mathrm{~cm}$ or up to 3 nodules all $\leq 3 \mathrm{~cm}$, is the benchmark adopted by most transplant centers $(47,48)$. Following transplant within the Milan criteria, overall 5 -year survival exceeds $70 \%$ with a $10-15 \%$ rate of recurrence (21). In the United States, the United Network for Organ Sharing (UNOS) adopted the Milan criteria to select HCC patients for transplant. Donor livers are preferentially allocated to recipients with the highest MELD scores; currently HCC patients with 1 nodule between $2-5 \mathrm{~cm}$ or 2-3 nodules all $\leq 3 \mathrm{~cm}$ are awarded 28 points 6 months after initially being listed, with 1-2 additional points awarded every 3 months until transplant. In addition to the Milan criteria, other groups have proposed "expanded" criteria for liver transplant. The University of California San Francisco (UCSF) criteria are the most widely-known and wellstudied. Under the UCSF criteria, patients are eligible for transplant if they have a solitary tumor up to $6.5 \mathrm{~cm}$, or up to 3 tumors all less than $4.5 \mathrm{~cm}$ with a total diameter less than $8 \mathrm{~cm}$. Initial results using the USCF criteria indicated 5 -year overall survival of $75 \%$ (49).

For patients awaiting transplant, bridging therapy should be considered if the anticipated wait-list time will be 6 months or longer (48). Proposed advantages of bridging therapy include maintaining disease control and decreasing the dropout rate while on the waiting list. In addition, the use bridging therapy may allow assessment of treatment response in the explanted liver at the time of transplant. Patients with a complete pathologic response demonstrate decreased recurrence 
and prolonged disease-free survival compared to incomplete responders (50). Trans-arterial chemoembolization or radiofrequency ablation represent the most commonly employed bridging therapies.

\section{Transplant versus resection}

Although liver transplant is the gold standard therapy for eligible patients that fall within Milan criteria, given the shortage of donor organs resection will often be considered, particularly in the setting of solitary lesions and very well compensated cirrhosis. There have been no randomized controlled trials comparing resection to transplant, with most reports consisting of single center retrospective studies (51-54). Most of these studies indicate a survival benefit to transplant, with one metaanalysis demonstrating a 5-year overall survival of 63\% for transplant compared to $53 \%$ for resection (55). Nevertheless, organ shortages have prompted some centers to pursue a resection first strategy in select patients, with salvage liver transplant (SLT) reserved for recurrences following resection. Several studies have indicated equivalent overall survival for patients that underwent primary liver transplant or resection followed by SLT $(56,57)$.

For patients with multiple liver lesions, the risks and benefits of resection must be weighed against other options including transplant, ablation, and regional therapies. In well-selected patients with multifocal disease, surgical resection can be performed safely, although these patients demonstrate decreased survival compared to resected solitary tumors $(58,59)$. Current EASL and AASLD guidelines recommend radiofrequency ablation for multifocal HCC within Milan that are not transplant candidates. Ablation can also be performed for larger tumors, although the best results likely occur in tumors $\leq 3 \mathrm{~cm}(60)$. Nevertheless, according to one propensity score-matched analysis, the 5-year recurrence-free survival following surgical resection was superior to radiofrequency ablation in resectable multifocal HCC ( $20.1 \%$ vs. 9.1\%, $p=0.001)$, although no difference was observed in 5 -year overall survival (36.3\% vs. $37.8 \%, p=0.609$ ) (61).

\section{Adjuvant therapy}

Following surgical treatment of HCC, currently there is no role for adjuvant therapy. In a phase III randomized controlled trial, sorafenib failed to demonstrate a benefit in recurrence-free survival compared to placebo after either resection or ablation (62). Multiple other agents have proven equally ineffective, including vitamin $\mathrm{K} 2$, retinoid, and systemic chemotherapy (63). Promising results with adjuvant autologous cytokine-induced killer cells or autologous dendritic cells suggest a potential role for immunotherapy, although these results require further investigation and validation $(64,65)$.

\section{REGIONAL THERAPY}

For patients that are not transplant or resection candidates, treatment with transarterial catheter directed therapy remains the best option. Generally, regional therapy is limited to patients with preserved liver function and multifocal liver nodules, large unresectable solitary lesions, or other tumors outside the Milan criteria (intermediate $\mathrm{HCC}, \mathrm{BCLC}$ stage B). The overall goal of treatment is to palliate symptoms and prolong life; cure is rarely possible in these patients. In select circumstances, regional therapy can downstage patients back within Milan criteria, and ultimately transplant may become an option.

\section{Transarterial therapy}

Multiple options exist for catheter-based embolic therapy, including transarterial embolization (TAE), transarterial chemoembolization (TACE), drug-eluting bead transarterial chemoembolization (DEB-TACE), and transarterial radioembolization (TARE) (table 2). The rational for catheter directed embolic therapy is based upon the dual blood supply to the liver. Normal liver parenchyma is predominantly perfused by portal flow; approximately $3 / 4$ of its blood supply arises from the portal vein, with the remaining $1 / 4$ from the hepatic arteries. On the other hand, primary liver tumors such as HCC receive the majority of their blood supply from the hepatic arteries. Therefore, arterially-directed therapies represent a strategy to selectively target hepatic tumors while sparing normal parenchyma.

The goal of TAE, or "bland embolization," is to completely occlude the arterial blood supply to the tumor, resulting in tissue hypoxia and cell death. Embolization is usually performed with gelatin sponge particles, polyvinyl alcohol spheres, or other embolic agents. TACE combines TAE with chemotherapy using lipiodol as the embolic agent. Popular chemotherapeutic agents include cisplatin, doxorubicin, epirubicin, and mitomycin C. TACE is often used in conjunction with bland embolization to increase tissue hypoxia and chemotherapy dwell time (66). DEB-TACE replaces lipiodol with microspheres impregnated with chemotherapy, usually doxorubicin (67). In general TAE, TACE, and DEB-TACE are indicated for intermediate $\mathrm{HCC}$ with preserved liver function, and are contraindicated in advanced or decompensated cirrhosis, patients with poor performance status, or those with significant 
Table 2 - Comparison of Arterially-Directed Liver Therapies

\begin{tabular}{|c|c|c|c|}
\hline Therapy & Description & Indications & Considerations \\
\hline $\begin{array}{l}\text { Transarterial } \\
\text { embolization (TAE) }\end{array}$ & $\begin{array}{l}\text { Bland embolization with occlusion } \\
\text { of tumor vascular bed using gelatin } \\
\text { sponge, polyvinyl alcohol spheres, } \\
\text { or other embolic agents }\end{array}$ & $\begin{array}{l}\text { - Intermediate HCC (BCLC B) } \\
\text { Contraindications } \\
\text { - Decompensated cirrhosis } \\
\text { - Bilirubin } \geq 4 \mathrm{mg} / \mathrm{dL} \\
\text { - Portal vein thrombus }\end{array}$ & $\begin{array}{l}\text { - Post-embolization syndrome } \\
\text { - Pulmonary embolus if portovenous shunt } \\
\text { - Comparable results to TACE }\end{array}$ \\
\hline $\begin{array}{l}\text { Transarterial } \\
\text { chemoembolization } \\
\text { (TACE) }\end{array}$ & $\begin{array}{l}\text { Lipiodiol acts as embolic agent and } \\
\text { carrier for cytotoxic chemotherapy }\end{array}$ & $\begin{array}{l}\text { - Intermediate HCC (BCLC B) } \\
\text { Contraindications } \\
\text { - Decompensated cirrhosis } \\
\text { - Bilirubin } \geq 4 \mathrm{mg} / \mathrm{dL} \\
\text { - Portal vein thrombus }\end{array}$ & $\begin{array}{l}\text { - Post-embolization syndrome } \\
\text { - TACE induced acute liver failure (2-20\%) } \\
\text { - Major complications (5\%): sepsis, non-target } \\
\text { embolization, biloma, biliary stricture }\end{array}$ \\
\hline $\begin{array}{l}\text { Drug-eluting bead } \\
\text { transarterial } \\
\text { chemoembolization } \\
\text { (DEB-TACE) }\end{array}$ & $\begin{array}{l}\text { Microspheres impregnated with } \\
\text { chemotherapy serve dual role as } \\
\text { embolic agent and delivery platform }\end{array}$ & $\begin{array}{l}\text { - Intermediate HCC (BCLC B) } \\
\text { Contraindications } \\
\text { - Decompensated cirrhosis } \\
\text { - Bilirubin } \geq 4 \mathrm{mg} / \mathrm{dL} \\
\text { - Portal vein thrombus }\end{array}$ & $\begin{array}{l}\text { - Similar complication profile as TACE, but } \\
\text { overall may be better tolerated } \\
\text { - May require fewer treatments }\end{array}$ \\
\hline $\begin{array}{l}\text { Transarterial } \\
\text { radioembolization } \\
\text { (TARE) }\end{array}$ & $\begin{array}{l}\text { Intra-arterial Yttrium } 90 \text { (90Y) allows } \\
\text { direct delivery of radiation to tumors } \\
\text { - Glass microspheres (TheraSphere) } \\
\text { - Resin microspheres (SIR-Spheres) }\end{array}$ & $\begin{array}{l}\text { - Intermediate HCC (BCLC B) } \\
\text { Contraindications } \\
\text { - Decompensated cirrhosis } \\
\text { - Bilirubin } \geq 2 \text { mg/dL } \\
\text { - Portosystemic shunts to } \\
\text { lungs/Gl tract }\end{array}$ & $\begin{array}{l}\text { - Requires pre-embolization mapping of } \\
\text { porto-venous shunts to prevent inadvertent } \\
\text { radiation to lungs or Gl tract } \\
\text { - Can be performed as outpatient and in } \\
\text { setting of portal vein thrombus } \\
\text { - May take up to } 3 \text { months to see response } \\
\text { on post-treatment imaging }\end{array}$ \\
\hline
\end{tabular}

Multiple options exist for trans-arterial therapy for hepatocellular carcinoma. There is no clear evidence demonstrating a clear superiority of one technique over another. The most common complication following therapy in post-embolization syndrome, characterized by self-limited nausea, abdominal pain/ileus, fever, and fatigue.

extra-hepatic metastases. Relative contraindications include biliary obstruction or a total bilirubin $>4 \mathrm{mg} / \mathrm{dL}$, renal insufficiency, or tumor involving the main portal veins (66). Often, repeat embolization will be necessary to achieve the best results.

Comparison of these modalities has failed to demonstrate any clear superiority of one embolization technique over any other. The only modality showing a trial proven survival benefit over conservative therapy is TACE, with improvements in 2-year survival ranging anywhere from $20 \%-60 \%$ and an increase in median survival from 16 to 20 months $(21,68,69)$. Although results are mixed, a meta-analysis comparing TAE and TACE suggests non-inferiority of TAE, and these therapies are considered relatively equivalent $(70,71)$. Additionally, TAE may have a cost advantage compared to other techniques (66). DEB-TACE has been shown to have similar survival benefits to TACE, as direct comparison of these modalities has failed to demonstrate a superior option regarding overall survival (72). However, DEB-TACE may be better tolerated with decreased toxicity (73)

TARE relies on delivery of radioactive spheres to the tumor bed, and the antitumor effect is induced by radiation instead of tissue hypoxia or chemotherapeutic effects. Yttrium-90 (Y-90) is a pure beta emitter with a tissue penetration up to $11 \mathrm{~mm}$, and can be delivered to the tumor via resin (SIR-Spheres) or glass (TheraSphere) microspheres $(66,74)$. In contrast to embolic therapies, Y-90 can be given in the setting of portal vein thrombosis $(75,76)$. Otherwise, Y-90 is best for intermediate HCC with compensated liver function, including a total bilirubin $<2 \mathrm{mg} / \mathrm{dL}$. Contraindications include renal insufficiency, decompensated cirrhosis, large tumor burden, and uncorrectable porto-systemic shunts to the lungs or gastrointestinal tract. For intermediate stage HCC, TARE provides survival outcomes comparable to TACE, although it may prolong time to progression compared to chemoembolization (77-79).

\section{SYSTEMIC THERAPY}

Patients with advanced HCC that is not amenable to regional therapy (BCLC stage $\mathrm{C}$ ) can be considered for systemic therapy. First-line therapy currently consists of sorafenib, a mutli-kinase inhibitor that effects multiple pathways involved in HCC. Sorafenib was approved for patients with advanced HCC following the results of the SHARP trial. Compared to placebo, sorafenib demonstrated an almost 3 month improvement in both overall survival (10.7 vs. 7.9 months, $\mathrm{p}<0.001$ ) and time to radiologic progression (5.5 vs. 2.8 months, $p<0.001$ ) (80). 
Recently, regorafenib was shown to provide a survival benefit in HCC patients that advanced on therapy with sorafenib, and regorafenib is now indicated as second-line therapy (81). Many other systemic agents have been investigated for treating HCC, including everolimus, brivanib, sunitinib, and bevacizumab. None have shown a clear advantage over sorafenib (82-85). Systemic cytotoxic chemotherapy has proven largely ineffective and is generally not used to treat HCC.

\section{Future directions}

Immunotherapy has been one the most exciting advances in cancer care over the last several years, and recent evidence suggests a role for immunotherapy in treating hepatocellular carcinoma. In a phase I/II trial of the PD-1 inhibitor nivolumab, patients with advanced HCC demonstrated a durable objective response rate up to $20 \%$, with a tolerable safety profile (86). Interim analysis revealed a median overall survival of 15.1 months, and close to half the patients survived longer than 18 months (87). Phase III trials evaluating nivolumab (NCT02576509) and pembrolizumab (NCT02702401) in advanced HCC are currently underway.

In addition to immunotherapy, researchers are evaluating multimodality treatments to improve survival in intermediate and advanced HCC. The addition of sorafenib to arterially directed therapies has been proposed as a synergistic combination that may improve survival (66). TACE has been shown to upregulate angiogenesis, which may be counteracted with sorafenib (88). Results have been mixed; despite some early promising single institution reports, no benefit was seen with the addition of sorafenib to TACE during several randomized trials (89). Nevertheless, a recent meta-analysis of 6 trials suggested an overall survival benefit to combination therapy (HR 0.64, 95\% Cl 0.43-0.97) (90). Similarly, the combination of TACE with ablation or external radiation has also been reported by numerous investigators. One review of 55 randomized trials concluded that the addition of ablation or external radiotherapy to chemoembolization significantly improved tumor response, and extended survival over chemoembolization alone (91). Among patients with unresectable HCC, the estimated median survival of TACE combined with ablation (33.3 months) or radiation therapy (30.1 months) was several months longer than transarterial therapies alone (TACE: 18 months; DEB-TACE: 20.6 months; TARE: 24.3 months) (91). Nevertheless, much of the available data continues to be relatively poor quality single-institution studies, and additional investigation will be needed to clarify the optimal multimodality strategies for HCC.

\section{CONCLUSION}

HCC remains a difficult disease to treat due to the heterogeneity of the underlying biology and the compromised liver function that accompanies most patients. There exists a wide range of potential therapeutic options, and an in many cases there is no clear evidence to guide treatment decisions. Careful consideration of the tumor biology, liver function, and the patient's performance status is required in order to risk-stratify patients and select the appropriate treatment, and these decisions should be made within the context of a multi-disciplinary tumor board. In the future, identification of tumor biomarkers and improved molecular profiling of these tumors may help match patients with the optimal therapies. Additionally, high-quality research in the comparative-effectiveness of the various treatment options and their combinations is ultimately needed in order to improve outcomes for these challenging patients.

\section{Disclosures}

All authors declare that they have no disclosures or conflicts of interest to report.

\section{REFERENCES}

1. Mittal S, El-Serag HB. Epidemiology of hepatocellular carcinoma: consider the population. J Clin Gastroenterol. 2013;47 Suppl:S2-6.

2. Sherman M. Hepatocellular carcinoma: epidemiology, surveillance, and diagnosis. Semin Liver Dis. 2010;30(1):3-16.

3. El-Serag HB, Davila JA, Petersen NJ, McGlynn KA. The continuing increase in the incidence of hepatocellular carcinoma in the United States: an update. Ann Intern Med. 2003;139(10):817-823.

4. Davila J, El-Serag H. The Rising Incidence of Hepatocellular Carcinoma in the United States: An Update. Gastroenterology. 2012; 142(Suppl 1):S914.

5. Fattovich G, Stroffolini T, Zagni I, Donato F. Hepatocellular carcinoma in cirrhosis: incidence and risk factors. Gastroenterology. 2004;127 (5 Suppl 1):S35-50.

6. Llovet JM, Zucman-Rossi J, Pikarsky E, Sangro B, Schwartz M, Sherman M, et al. Hepatocellular carcinoma. Nat Rev Dis Primers. 2016;2:16018. doi: 10.1038/nrdp.2016.18.

7. Novikova MV, Khromova NV, Kopnin PB. Components of the Hepatocellular Carcinoma Microenvironment and Their Role in Tumor Progression. Biochemistry (Mosc). 2017;82(8):861-873.

8. Schlageter M, Terracciano LM, D'Angelo S, Sorrentino P. Histopathology of hepatocellular carcinoma. World J Gastroenterol. 2014;20(43):15955-15964.

9. Shafizadeh N, Kakar S. Hepatocellular Carcinoma: Histologic Subtypes. Surg Pathol Clin. 2013;6(2):367-384.

10. Torbenson MS. Morphologic Subtypes of Hepatocellular Carcinoma. Gastroenterol Clin North Am. 2017;46(2):365-391.

11. Pathologic diagnosis of early hepatocellular carcinoma: a report of the international consensus group for hepatocellular neoplasia. Hepatology. 2009;49(2):658-664.

12. Kojiro M. Histopathology of liver cancers. Best Pract Res Clin Gastroenterol. 2005;19(1):39-62.

13. Lafaro KJ, Pawlik TM. Fibrolamellar hepatocellular carcinoma: current clinical perspectives. J Hepatocell Carcinoma. 2015;2:151-7. doi: 10.2147/JHC.S75153. eCollection 2015 
14. Varela M, Sala M, Llovet JM, Bruix J. Review article: natural history and prognostic prediction of patients with hepatocellular carcinoma. Aliment Pharmacol Ther. 2003;17 Suppl 2:98-102.

15. Khalaf N, Ying J, Mittal S, Temple S, Kanwal F, Davila J, et al. Natural History of Untreated Hepatocellular Carcinoma in a US Cohort and the Role of Cancer Surveillance. Clin Gastroenterol Hepatol. 2017;15(2): 273-281.e1. doi: 10.1016/j.cgh.2016.07.033. Epub 2016 Aug 10.

16. Singal A, Volk ML, Waljee A, Salgia R, Higgins P, Rogers MA, et al. Meta-analysis: surveillance with ultrasound for early-stage hepatocellular carcinoma in patients with cirrhosis. Aliment Pharmacol Ther. 2009;30(1):37-47. doi: 10.1111/j.1365-2036.2009.04014.x. Epub 2009 Apr 8.

17. Zhang BH, Yang BH, Tang ZY. Randomized controlled trial of screening for hepatocellular carcinoma. J Cancer Res Clin Oncol. 2004;130(7):417-422.

18. EASL-EORTC clinical practice guidelines: management of hepatocellular carcinoma. J Hepatol. 2012;56(4):908-943.

19. Tang A, Bashir MR, Corwin MT, et al. Evidence Supporting LI-RADS Major Features for CT- and MR Imaging-based Diagnosis of Hepatocellular Carcinoma: A Systematic Review. Radiology. 2018;286(1):29-48.

20. Santillan CS, Tang A, Cruite I, Shah A, Sirlin CB. Understanding L I-RADS: a primer for practical use. Magn Reson Imaging Clin N Am. 2014;22(3):337-352.

21. Forner A, Reig M, Bruix J. Hepatocellular carcinoma. Lancet. 2018;391(10127):1301-1314

22. Abdel-Rahman 0. Assessment of the discriminating value of the 8th AJCC stage grouping for hepatocellular carcinoma. HPB (Oxford). 2018;20(1):41-48.

23. Okuda K, Ohtsuki T, Obata H, Tomimatsu M, Okazaki N, Hasegawa $\mathrm{H}$, et al. Natural history of hepatocellular carcinoma and prognosis in relation to treatment. Study of 850 patients. Cancer. 1985; 56(4):918-28.

24. Chevret S, Trinchet JC, Mathieu D, Rached AA, Beaugrand M, Chastang C. A new prognostic classification for predicting survival in patients with hepatocellular carcinoma. Groupe d'Etude et de Traitement du Carcinome Hepatocellulaire. J Hepatol. 1999;31(1): 133-141.

25. Leung TW, Tang AM, Zee B, Lau WY, Lai PB, Leung KL, et al Construction of the Chinese University Prognostic Index for hepatocellular carcinoma and comparison with the TNM staging system, the Okuda staging system, and the Cancer of the Liver Italian Program staging system: a study based on 926 patients. Cancer. 2002;94(6):1760-9.

26. Kudo M, Chung H, Osaki Y. Prognostic staging system for hepatocellular carcinoma (CLIP score): its value and limitations, and a proposal for a new staging system, the Japan Integrated Staging Score (JIS score). J Gastroenterol. 2003;38(3):207-215.

27. A new prognostic system for hepatocellular carcinoma: a retrospective study of 435 patients: the Cancer of the Liver Italian Program (CLIP) investigators. Hepatology. 1998;28(3):751-755.

28. Llovet JM, Bru C, Bruix J. Prognosis of hepatocellular carcinoma: the BCLC staging classification. Semin Liver Dis. 1999;19(3):329338.

29. Zamora-Valdes D, Taner T, Nagorney DM. Surgical Treatment of Hepatocellular Carcinoma. Cancer Control. 2017;24(3): 1073274817729258

30. Sim HW, Knox J, Dawson LA. An Update on Randomized Clinical Trials in Hepatocellular Carcinoma. Surg Oncol Clin N Am. 2017; 26(4):647-666

31. Teh SH, Christein J, Donohue J, Que F, Kendrick M, Farnell M, et al Hepatic resection of hepatocellular carcinoma in patients with cirrhosis: Model of End-Stage Liver Disease (MELD) score predicts perioperative mortality. J Gastrointest Surg. 2005;9(9):1207-15; discussion 1215

32. Bruix J, Castells A, Bosch J, Feu F, Fuster J, Garcia-Pagan JC, et al. Surgical resection of hepatocellular carcinoma in cirrhotic patients: prognostic value of preoperative portal pressure. Gastroenterology. 1996;111(4):1018-22.

33. Cescon M, Colecchia A, Cucchetti A, Peri E, Montrone L, Ercolani G, et al. Value of transient elastography measured with FibroScan in predicting the outcome of hepatic resection for hepatocellular carcinoma. Ann Surg. 2012;256(5):706-12; discussion 712-3. doi: 10.1097/SLA.0b013e3182724ce8.

34. Shi M, Guo RP, Lin XJ, Zhang YQ, Chen MS, Zhang CQ, et al. Partial hepatectomy with wide versus narrow resection margin for solitary hepatocellular carcinoma: a prospective randomized trial. Ann Surg. 2007;245(1):36-43

35. Glantzounis GK, Tokidis E, Basourakos SP, Ntzani EE, Lianos GD, Pentheroudakis $\mathrm{G}$. The role of portal vein embolization in the surgical management of primary hepatobiliary cancers. A systematic review. Eur J Surg Oncol. 2017;43(1):32-41.

36. Zhou Y, Lei X, Wu L, Wu X, Xu D, Li B. Outcomes of hepatectomy for noncirrhotic hepatocellular carcinoma: a systematic review. Surg Oncol. 2014;23(4):236-242.

37. Schwartz ME, Shrager B. Surgical resection for hepatocellular carcinoma in the noncirrhotic: the Western experience. Recent Results Cancer Res. 2013;190:85-100. doi: 10.1007/978-3-64216037-0 6 .

38. Ettorre GM, Levi Sandri GB, Colasanti M, Mascianà G, de Werra E, Santoro R, et al. Liver resection for hepatocellular carcinoma $\geq 5 \mathrm{~cm}$. Transl Gastroenterol Hepatol. 2017 Mar 24;2:22. doi: 10.21037/ tgh.2017.03.13. eCollection 2017.

39. Pandey D, Lee KH, Wai CT, Wagholikar G, Tan KC. Long term outcome and prognostic factors for large hepatocellular carcinoma (10 $\mathrm{cm}$ or more) after surgical resection. Ann Surg Oncol. 2007;14(10): 2817-23. Epub 2007 Aug 10.

40. Arnaoutakis DJ, Mavros MN, Shen F, Alexandrescu S, Firoozmand A, Popescu I, et al. Recurrence patterns and prognostic factors in patients with hepatocellular carcinoma in noncirrhotic liver: a multiinstitutional analysis. Ann Surg Oncol. 2014;21(1):147-154. doi: 10.1245/s10434-013-3211-3.

41. Faber W, Sharafi S, Stockmann M, Denecke T, Sinn B, Puhl G, et al. Long-term results of liver resection for hepatocellular carcinoma in noncirrhotic liver. Surgery. 2013;153(4):510-7. doi: 10.1016/j.surg. 2012.09.015. Epub 2012 Nov 1.

42. Chen MS, Li JQ, Zheng Y, Guo RP, Liang HH, Zhang YQ, et al. A prospective randomized trial comparing percutaneous local ablative therapy and partial hepatectomy for small hepatocellular carcinoma. Ann Surg. 2006;243(3):321-8.

43. Huang J, Yan L, Cheng Z, Wu H, Du L, Wang J, et al. A randomized trial comparing radiofrequency ablation and surgical resection for HCC conforming to the Milan criteria. Ann Surg. 2010;252(6):90312. doi: $10.1097 / S L A .0 b 013 e 3181$ efc656.

44. Feng K, Yan J, Li X, Xia F, Ma K, Wang S, et al. A randomized controlled trial of radio-frequency ablation and surgical resection in the treatment of small hepatocellular carcinoma. J Hepatol. 2012;57(4):794-802. doi: 10.1016/j.jhep.2012.05.007. Epub 2012 May 23.

45. Liu PH, Hsu CY, Hsia CY, Lee YH, Huang YH, Chiou YY, et al. Surgical Resection Versus Radiofrequency Ablation for Single Hepatocellular Carcinoma $\leq 2 \mathrm{~cm}$ in a Propensity Score Model. Ann Surg. 2016;263(3):538-45. doi: 10.1097/SLA.0000000000001178.

46. Mehta N, Sarkar M, Dodge JL, Fidelman N, Roberts JP, Yao FY. Intention to treat outcome of T1 hepatocellular carcinoma with the "wait and not ablate" approach until meeting T2 criteria for liver transplant listing. Liver Transpl. 2016;22(2):178-187.

47. Mazzaferro V, Regalia E, Doci R, Andreola S, Pulvirenti A, Bozzetti F, et al. Liver transplantation for the treatment of small hepatocellular carcinomas in patients with cirrhosis. N Engl J Med. 1996;334(11): 693-9.

48. Clavien PA, Lesurtel M, Bossuyt PM, Gores GJ, Langer B, Perrier A. Recommendations for liver transplantation for hepatocellular carcinoma: an international consensus conference report. Lancet Oncol. 2012:13(1):e11-22.

49. Yao FY, Ferrell L, Bass NM, Watson JJ, Bacchetti P, Venook A, et al. Liver transplantation for hepato-cellular carcinoma: expansion of the tumor size limits does not adversely impact survival. Hepatology. 2001;33(6):1394-403

50. Agopian VG, Harlander-Locke MP, Ruiz RM, Klintmalm GB, Senguttuvan S, Florman SS, et al. Impact of Pretransplant Bridging Locoregional Therapy for Patients With Hepatocellular Carcinoma Within Milan Criteria Undergoing Liver Transplantation: Analysis of 
3601 Patients From the US Multicenter HCC Transplant Consortium. Ann Surg. 2017;266(3):525-535.

51. Shah SA, Cleary SP, Tan JC, Wei AC, Gallinger S, Grant DR, et al. An analysis of resection vs transplantation for early hepatocellular carcinoma: defining the optimal therapy at a single institution. Ann Surg Oncol. 2007;14(9):2608-14. Epub 2007 May 24.

52. Llovet JM, Fuster J, Bruix J. Intention-to-treat analysis of surgical treatment for early hepatocellular carcinoma: resection versus transplantation. Hepatology. 1999;30(6):1434-40.

53. Adam R, Bhangui P, Vibert E, Azoulay D, Pelletier G, Duclos-Vallée $\mathrm{JC}$, et al. Resection or transplantation for early hepatocellular carcinoma in a cirrhotic liver: does size define the best oncological strategy? Ann Surg. 2012;256(6):883-91.

54. Koniaris LG, Levi DM, Pedroso FE, Franceschi D, Tzakis AG, Santamaria-Barria JA, et al. Is surgical resection superior to transplantation in the treatment of hepatocellular carcinoma? Ann Surg. 2011;254(3):527-37; discussion 537-8.

55. Dhir M, Lyden ER, Smith LM, Are C. Comparison of outcomes of transplantation and resection in patients with early hepatocellular carcinoma: a meta-analysis. HPB (Oxford). 2012;14(9):635-645.

56. Hu Z, Wang W, Li Z, Ye S, Zheng SS. Recipient outcomes of salvage liver transplantation versus primary liver transplantation: a systematic review and meta-analysis. Liver Transpl. 2012;18(11): 1316-1323.

57. Muaddi H, Al-Adra DP, Beecroft R, Ghanekar A, Moulton CA, Doyle A, et al. Liver Transplantation is Equally Effective as a Salvage Therapy for Patients with Hepatocellular Carcinoma Recurrence Following Radiofrequency Ablation or Liver Resection with Curative Intent. Ann Surg Oncol. 2018;25(4):991-999. doi: 10.1245/s10434017-6329-x. Epub 2018 Jan 11.

58. Ng KK, Vauthey JN, Pawlik TM, Lauwers GY, Regimbeau JM, Belghiti $\mathrm{J}$, et al. Is hepatic resection for large or multinodular hepatocellular carcinoma justified? Results from a multi-institutional database. Ann Surg Oncol. 2005;12(5):364-73. Epub 2005 Mar 31.

59. Ishizawa T, Hasegawa K, Aoki T, Takahashi M, Inoue Y, Sano K, et al. Neither multiple tumors nor portal hypertension are surgical contraindications for hepatocellular carcinoma. Gastroenterology. 2008; 134(7):1908-16. doi: 10.1053/.gastro.2008.02.091. Epub 2008 Mar 8.

60. Hirano G, Iwata K, Anan A, Sohda T, Kunimoto H, Yotsumoto K, et al. Why is radiofrequency ablation therapy applied for hepatocellular carcinoma up to 3 nodules and smaller than $3 \mathrm{~cm}$ in tumor size? Hepatogastroenterology. 2014; 61(136):2305-10.

61. Jiang L, Yan L, Wen T, Li B, Zeng Y, Yang J, et al. Comparison of Outcomes of Hepatic Resection and Radiofrequency Ablation for Hepatocellular Carcinoma Patients with Multifocal Tumors Meeting the Barcelona-Clinic Liver Cancer Stage A Classification. J Am Coll Surg. 2015;221(5):951-61. doi: 10.1016/j.jamcollsurg.2015.08.009. Epub 2015 Aug 20

62. Bruix J, Takayama T, Mazzaferro V, Chau GY, Yang J, Kudo M, et al. Adjuvant sorafenib for hepatocellular carcinoma after resection or ablation (STORM): a phase 3, randomised, double-blind, placebocontrolled trial. Lancet Oncol. 2015;16(13):1344-54. doi: 10.1016/ S1470-2045(15)00198-9. Epub 2015 Sep 8.

63. Lu LC, Cheng AL, Poon RT. Recent advances in the prevention of hepatocellular carcinoma recurrence. Semin Liver Dis. 2014;34(4): 427-434.

64. Lee JH, Lee JH, Lim YS, Yeon JE, Song TJ, Yu SJ, et al. Adjuvant immunotherapy with auto-logous cytokine-induced killer cells for hepatocellular carcinoma. Gastroenterology. 2015;148(7):1383-91.e6. doi: 10.1053/j.gastro.2015.02.055. Epub 2015 Mar 4.

65. Lee JH, Tak WY, Lee Y, Heo MK, Song JS, Kim HY, et al. Adjuvant immunotherapy with autologous dendritic cells for hepatocellular carcinoma, randomized phase II study. Oncoimmunology. 2017; 6(7): e1328335. doi: 10.1080/2162402X.2017.1328335. eCollection 2017.

66. Gbolahan OB, Schacht MA, Beckley EW, LaRoche TP, O'Neil BH, Pyko M. Locoregional and systemic therapy for hepatocellular carcinoma. J Gastrointest Oncol. 2017;8(2):215-228.

67. Lewis AL, Gonzalez MV, Lloyd AW, Hall B, Tang Y, Willis SL, et al. DC bead: in vitro characterization of a drug-delivery device for transarterial chemoembolization. J Vasc Interv Radiol. 2006;17(2 Pt 1): $335-42$.
68. Lo CM, Ngan H, Tso WK, Liu CL, Lam CM, Poon RT, et al. Randomized controlled trial of transarterial lipiodol chemoembolization for unresectable hepatocellular carcinoma. Hepatology. 2002;35(5):1164-71.

69. Llovet JM, Bruix J. Systematic review of randomized trials for unresectable hepatocellular carcinoma: Chemoembolization improves survival. Hepatology. 2003;37(2):429-442.

70. Okusaka T, Kasugai H, Shioyama Y, Tanaka K, Kudo M, Saisho H, et al. Transarterial chemotherapy alone versus transarterial chemoembolization for hepatocellular carcinoma: a randomized phase III trial. J Hepatol. 2009;51(6):1030-6. doi: 10.1016/j.jhep.2009.09.004. Epub 2009 0ct 1.

71. Marelli L, Stigliano R, Triantos C, Senzolo M, Cholongitas E, Davies $\mathrm{N}$, et al. Transarterial therapy for hepatocellular carcinoma: which technique is more effective? A systematic review of cohort and randomized studies. Cardiovasc Intervent Radiol. 2007;30(1):6-25.

72. Golfieri R, Giampalma E, Renzulli M, Cioni R, Bargellini I, Bartolozzi $\mathrm{C}$, et al. Randomised controlled trial of doxorubicin-eluting beads vs conventional chemoembolisation for hepatocellular carcinoma. $\mathrm{Br} \mathrm{J}$ Cancer. 2014;111(2):255-64. doi: 10.1038/bjc.2014.199. Epub 2014 Jun 17.

73. Lammer J, Malagari K, Vogl T, Pilleul F, Denys A, Watkinson A, et al. Prospective randomized study of doxorubicin-eluting-bead embolization in the treatment of hepatocellular carcinoma: results of the PRECISION V study. Cardiovasc Intervent Radiol. 2010;33(1):41-52. doi: 10.1007/s00270-009-9711-7. Epub 2009 Nov 12.

74. Salem R, Lewandowski RJ, Sato KT, Atassi B, Ryu RK, Ibrahim S, et al. Technical aspects of radioembolization with $90 \mathrm{Y}$ microspheres. Tech Vasc Interv Radiol. 2007;10(1):12-29.

75. Kulik LM, Carr BI, Mulcahy MF, Lewandowski RJ, Atassi B, Ryu RK, et al. Safety and efficacy of $90 \mathrm{Y}$ radiotherapy for hepatocellular carcinoma with and without portal vein thrombosis. Hepatology. 2008;47(1):71-81.

76. Garin E, Rolland Y, Edeline J, Icard N, Lenoir L, Laffont S, et al. Personalized dosimetry with intensification using 90Y-loaded glass microsphere radioembolization induces prolonged overall survival in hepatocellular carcinoma patients with portal vein thrombosis. J Nucl Med. 2015;56(3):339-46. doi: 10.2967/jnumed.114.145177. Epub 2015 Feb 12.

77. Salem R, Gordon AC, Mouli S, Hickey R, Kallini J, Gabr A, et al. Y90 Radioembolization Significantly Prolongs Time to Progression Compared With Chemoembolization in Patients With Hepatocellular Carcinoma. Gastroenterology. 2016;151(6):1155-1163.e2. doi: 10.1053/j.gastro.2016.08.029. Epub 2016 Aug 27.

78. Salem R, Lewandowski RJ, Mulcahy MF, Riaz A, Ryu RK, Ibrahim S, et al. Radioembolization for hepatocellular carcinoma using Yttrium90 microspheres: a comprehensive report of long-term outcomes. Gastroenterology. 2010;138(1):52-64. doi: 10.1053/j.gastro.2009.09. 006. Epub 2009 Sep 18.

79. Sangro B, Carpanese L, Cianni R, Golfieri R, Gasparini D, Ezziddin S, et al. Survival after yttrium-90 resin microsphere radioembolization of hepatocellular carcinoma across Barcelona clinic liver cancer stages: a European evaluation. Hepatology. 2011;54(3):868-78. doi: 10.1002/hep.24451. Epub 2011 Jun 30.

80. Llovet JM, Ricci S, Mazzaferro V, Hilgard P, Gane E, Blanc JF, et al. Sorafenib in advanced hepatocellular carcinoma. N Engl J Med. 2008;359(4):378-90. doi: 10.1056/NEJMoa0708857.

81. Bruix J, Qin S, Merle P, Granito A, Huang YH, Bodoky G, et al. Regorafenib for patients with hepatocellular carcinoma who progressed on sorafenib treatment (RESORCE): a randomised, double-blind, placebo-controlled, phase 3 trial. Lancet. 2017; 389(10064):56-66. doi: 10.1016/S0140-6736(16)32453-9. Epub 2016 Dec 6.

82. Fang $\mathrm{P}, \mathrm{Hu} \mathrm{JH}$, Cheng ZG, Liu ZF, Wang JL, Jiao SC. Efficacy and safety of bevacizumab for the treatment of advanced hepatocellular carcinoma: a systematic review of phase II trials. PLOS One. 2012;7(12):e49717. doi: 10.1371/journal.pone.0049717. Epub 2012 Dec 19.

83. Johnson PJ, Qin S, Park JW, Poon RT, Raoul JL, Philip PA, et al. Brivanib versus sorafenib as first-line therapy in patients with unresectable, advanced hepatocellular carcinoma: results from the randomized phase III BRISK-FL study. J Clin Oncol. 2013;31(28): 
3517-24. doi: 10.1200/JC0.2012.48.4410. Epub 2013 Aug 26.

84. Cheng AL, Kang YK, Lin DY, Park JW, Kudo M, Qin S, et al. Sunitinib versus sorafenib in advanced hepatocellular cancer: results of a randomized phase III trial. J Clin Oncol. 2013;31(32):4067-75. doi: 10.1200/JC0.2012.45.8372. Epub 2013 Sep 30.

85. Zhu AX, Kudo M, Assenat E, Cattan S, Kang YK, Lim HY, et al. Effect of everolimus on survival in advanced hepatocellular carcinoma after failure of sorafenib: the EVOLVE-1 randomized clinical trial. JAMA. 2014;312(1):57-67. doi: 10.1001/jama.2014.7189.

86. El-Khoueiry AB, Sangro B, Yau T, Crocenzi TS, Kudo M, Hsu C, et al. Nivolumab in patients with advanced hepatocellular carcinoma (CheckMate 040): an open-label, non-comparative, phase 1/2 dose escalation and expansion trial. Lancet. 2017; 389(10088): 2492-2502. doi: 10.1016/S0140-6736(17)31046-2. Epub 2017 Apr 20.

87. El-Khoueiry AB, Sangro B, Yau TC, et al. Phase I/II safety and antitumor activity of nivolumab (nivo) in patients (pts) with advanced hepatocellular carcinoma (HCC): Interim analysis of the CheckMate040 dose escalation study. J Clin Oncol. 2016;34(suppl; abstr 4012).
88. Sergio A, Cristofori C, Cardin R, Pivetta G, Ragazzi R, Baldan A, et al. Transcatheter arterial chemoembolization (TACE) in hepatocellular carcinoma (HCC): the role of angiogenesis and invasiveness. Am J Gastroenterol. 2008; 103(4):914-21. doi: 10.1111/j.1572-0241. 2007.01712.x. Epub 2008 Jan 2.

89. Kudo M, Arizumi T. Transarterial Chemoembolization in Combination with a Molecular Targeted Agent: Lessons Learned from Negative Trials (Post-TACE, BRISK-TA, SPACE, ORIENTAL, and TACE-2). Oncology. 2017;93 Suppl 1:127-134.

90. Yang M, Yuan JQ, Bai M, Han GH. Transarterial chemoembolization combined with sorafenib for unresectable hepatocellular carcinoma: a systematic review and meta-analysis. Mol Biol Rep. 2014; 41(10):6575-6582.

91. Katsanos K, Kitrou P, Spiliopoulos S, Maroulis I, Petsas T, Karnabatidis D. Comparative effectiveness of different transarterial embolization therapies alone or in combination with local ablative or adjuvant systemic treatments for unresectable hepatocellular carcinoma: A network meta-analysis of randomized controlled trials. PLoS One. 2017;12(9):e0184597. 